\title{
Evolution of partnering relationships: a supply chain perspective
}

\author{
B.A.Wagner and M.D. Murphy \\ Centre for Supply Chain Management \\ West of Scotland Science Park, 1 Todd Campus, Maryhill Road, \\ Glasgow. G20 0XA \\ Tel: 01419456461 Fax: 01419450427 \\ E. Haughey \\ IDV Operations Ireland Limited \\ Nangor House, Western Estate, Dublin 12, Ireland \\ Tel: 0035314051351 Fax: 0035314051333
}




\begin{abstract}
Partnering as a concept has supposedly come of age. Many organisations preach the partnering message and proclaim the benefits of working in this way. The reality in too many instances is that partnering like some other management solutions is merely a label to describe a way of doing business that has changed little from what most people would understand as a traditional arm's-length relationship. Whilst theoretically the benefits of partnering should be able to be realised, many organisations are frustrated in their attempts to reduce cost and add value to the supply chain in this way. Partnering is an all embracing business philosophy that has fundamental implications for how organisations behave and do business with each other.
\end{abstract}

This paper reviews the theory of partnering in the context of the supply chain, explains that partnering will not happen by accident and that a properly managed process is required to steer the organisations through the various stages of the partnering life cycle. The issues of managing across boundaries are complex and require a different way of thinking and behaving. Most organisations are ill equipped to cope with the necessary changes to make partnering effective and sustainable. This paper will address what the theoretical literature has to say, about partnering and its concept and philosophy, the implications for @SCMG Ltd's SCIP process in the context of a partnering life cycle and decision points for exiting such a relationship

Key Words

Customer/supplier relationships, supply chain implementation process (SCIP), partnering life cycle

\title{
1 INTRODUCTION
}

Partnering within the supply chain, is increasingly being recognised as strategically and operationally important, however the issues concerning most companies are how to implement partnering within their supply chain. These kinds of relations are characterised by sourcing from fewer suppliers with the aim of commercial advantage arising from collaboration. Fostering mutual trust and long-term commitment (Speckman and Johnston 1986) should mean cost reduction, added value and improved performance. Improved relations is the synergy created as a result of the two organisations working together to resolve common problems and to achieve common goals (Hastings 1993). 


\section{WHAT THEORETICAL LITERATURE HAS TO SAY ABOUT PARTNERING}

In essence cooperative relationships are discrete arrangements whereby organisations share a measure of administrative authority, form social links, and accept joint agreement regarding the shaping of operating policies. Partnering also implies more open ended arrangements to replace highly specific, arm's-length contacts and the elimination of barriers so as to permit quicker flow of knowledge (Porter 1986 :345-365). The concept of integrated logistics management, whereby the flow of information and materials between source and user are coordinated and managed as a unified system, is now better understood, if not widely practiced. The logic of linking each step of the process is based upon principles of optimisation (Bowersox and Closs 1996). In other words, the goal is to improve customer service whilst minimising costs and freeing up assets in the logistical pipeline (Christopher 1992:187). However, few recognise how extreme a paradigm shift is required to reap these benefits (Macbeth 1993:215). Such interaction is coordinated by cross functional teams (Dimancescu 1992) and the emphasis is changing from functionality to process orientation as the lowest common denominator for organisations and their supply chains. The role for individuals and job specifications are changing dramatically.

\section{THE PARTNERING CONCEPT AND PHILOSOPHY}

Although Industrial and business literature contains numerous definitions and interpretations of supplier partnering (Porter 1980; Carlisle and Parker 1989; Sako 1992; Lamming 1993; Macbeth et al 1994; Kanter 1994) this kind of partnering is characterised by longer-term, close working relations between suppliers and buyers. It involves many aspects including sharing risks and rewards (Ellram 1991), cooperation (Spekman 1988), single source supplier, readiness to compromise in negotiations, pragmatic strategic relationships (Mohr and Spekman 1994), blurred boundaries (Kanter 1988), and new organisational paradigm (Macbeth et al 1993). Other writers have identified important partnering characteristics as commitment, co-ordination, interdependence and trust (see for example Pfeffer and Salancik 1987, Sako 1992). The initiative may be taken by the customer or supplier although the instances where suppliers drive the partnering process from the start are exceptional. It is still seen as the customers' prerogative to choose the partner-supplier. Customers are realistic and understand that in the same way that they have preferred suppliers, suppliers also have preferred customers.

The boundaries between and within organisations are becoming increasingly blurred to the extent that companies can be customers, suppliers and competitors at the same time. The rules of the game are changing and the way in which 
competition is defined is also changing. Seen in this light, partnering with suppliers is not the end in itself but is rather the means of increasing performance and adding value by cooperative action. It is not a panacea for fundamental marketing and production problems and certainly not a soft option (Chadwick and Ragagopal 1995:100). There are no short cuts in developing customer-supplier relationships and a business relationship is seldom instantly altered by a single event. A structured sequential plan of action is required if enthusiasm and trust are to be built. (C) SCMG Ltd's experience suggests the Supply Chain Improvement Process (SCIP) can be developed into a five step structured and managed process.

Phase 1: Internal commitment and team building

Phase 2: Partner selection

Phase 3: Supplier commitment and communication

Phase 4: Relationship measurement and analysis

Phase 5: Action implementation and progress review

\section{DISCUSSION}

The evidence for this paper has been compiled from several years research and consultancy experience, working with customer and supplier organisations through various phases of the partnering process, although not always specifically defined in such absolute terms. During this time, a pattern has emerged indicating that a life cycle may be one aspect not previously considered or fully understood. A life cycle perspective may be useful to those pursuing partnering as an indicator of what might be expected to occur during the process. It is intended as a guide during the implementation stages and describes expectations and benefits that may be achieved, although not specifically in any particular stage or time frame.

\subsection{THE PARTNERING LIFE CYCLE}

\section{Stage I:Comprehension}

Cross functional teams are formed and tasked with various projects to achieve specific purposes. Keeping in sight strategic objectives set out in the partnering agreement, team members develop their own project plan, milestones, group performance measures and monitoring and evaluation procedures. Success depends on how well a team understands its own objectives and also on management's commitment to allocate resources to enable the teams to operate.

The team must be empowered with the authority to make all business decisions relevant to its task. Developing understanding of a partners business and why things happen in particular ways is the start of the long road to building trust between the 
two organisations. The mandated teams facilitate this learning through closer working relations.

\section{Stage II: Integration}

The integration phase is when customer and supplier organisations together begin to see activities in the other company as part of a connected process. This is the period of most intense activity and the partnering process has to be strongly encouraged by motivated management champions. During this phase activities are shared and mutual ownership is nurtured. Managing processes by use of cross functional teams means that people involved in the mechanics of the business are better able to see the overall picture and exactly what is required of them.

\section{Stage III: Consolidation}

The consolidation phase can be identified by a deceleration of both activity and motivation. During this stage the project teams accomplish the objectives that have 'so strongly driven individuals since the outset of the partnering process. As performance begins to plateau, it is a time to review the achievements of the past, to consolidate remaining projects and to reflect on the future of the relationship. By this time the relationship should have matured to such an extent that a new philosophy and culture has permeated each company, so that teamwork is seen as the way to do business and changed behaviour is evident in the daily tasks and responsibilities of many people.

\section{Phase IV: Mature Progression}

Significant progression is only achieved by doing things differently rather than doing the same things better. A different way of working now emerges with relations based on first hand experience and the building of trust. While new project teams may be implemented and tasks allocated, because their activities are so varied, the teams are likely to achieve specific objectives and then disband. The mature progression phase is therefore slower than the previous three phases and during this period partnering firms must begin to develop definite and perhaps unique relationship specific competencies to stay ahead of the pack.

\section{Exit Point 1}

The complexities of partnering only compound the comprehension issues as individuals and groups really have to think and behave fundamentally differently. The most probable reason to exit is due to lack of clear purpose and management commitment. Although this may not be stated publicly many organisations change 
the labels and just do what they always did. Corporate inertia may also stifle any new initiative which threatens the status quo. The probability of companies progressing to Stage 2 of the partnering life cycle is $60 \%$.

\section{Exit Point 2}

Clear purpose is required to progress to the integration stage. Integration may take place at different levels however the glue that holds things together at this stage is properly coordinated cross functional teams. Very few organisations pay sufficient attention to the social needs of the partnering team and incompatibility between objectives and reward as well as turnover in personnel are serious threats to moving to the next stage. The probability of companies progressing to Stage 3 is no better than $40 \%$.

\section{Exit Point 3}

The consolidation stage requires a review of the strategic direction of the relationship. The quick wins have been achieved. Performance is now reliable, sustainable and high, however, as the process develops both sides become more aware of fundamental things that they do differently which are barriers to improving the relationship. This is a water shed in the relationship. Investment requirements or commitment to a long term joint future to justify additional investment will be the most significant barriers to change at this stage. The probability of organisations progressing to Stage 4 is $10 \%$.

\section{Exit Point 4}

Total cost reductions will be the most dramatic in Stage 4 . This will only be possible when both partners develop a transparent and open understanding of the cost drivers in their relationship. The relationship will mature and an optimistic although critical philosophy will provide the catalyst and the enthusiasm to challenge every aspect of each others business. There are still some factors beyond the control of both parties which may dictate an exit from the relationship. Technological leadership on one hand provides a reason to cooperate but at the same time this is a high risk factor in technology dependent fast moving sectors as part of the reasons for behaving cooperatively is that these threats and opportunities can be managed together. 


\subsection{CONCLUSION}

The process of partnering is generic. Different companies in different sectors will have context specific problems they must address. A properly defined and managed process is required to ensure that the proper foundations are in place to sustain the longer term agenda and investment requirements. Many companies do not properly define the improvement process or they may choose to adopt the new label but not the philosophy, putting in jeopardy their market credibility and longer term supply chain performance. The partnering life cycle provides a framework which indicates to companies the perils and pitfalls of the process whether managed or not. The majority of organisations who claim to be partnering are not doing so, and do not understand the profound implications that the approach can have for their competitiveness. Managing a supply chain on a cooperative basis is the most difficult behavioural decision for many individuals and organisations, although it is often referred to a the soft or cosy option.

Many organisations still recruit, train and reward based on an adversarial model despite the sea change in dependency relationships in the supply chain. Many outsourced and right sized customers are finding it difficult to come to terms with the new supply chain order where perhaps their previously "weak" and highly dependent suppliers now have alternative preferred customers who they do business with. Although not fully understood many organisations have high mutual dependency on supply chain processes which provide them with routes to market and sources of supply. The lowest common denominator is now the process and not departmental functions.

Groups and individuals will have to behave and operate differently if they are to participate fully in the process rather than meet some suboptimised functional objectives. Supply chain improvement can only be facilitated through cross functional teams who can work in cooperation to ensure that the supply chain process does add value and quality at every step to ensure customer and supplier satisfaction. A clear mandate is required from senior managers to empower teams to deliver mutual benefits.

Even with a properly managed process only $5 \%$ of companies will realise the benefits of the mature progression stage. $95 \%$ of cooperating companies will never realise the full return on their investment and will end up seeing partnering only as a resource and time hungry activity. Most organisations are prisoners of their past history of adversarial relationships with suppliers (and customers). These companies are increasingly becoming the underperformers and are eroding their competitive advantage. Successful companies today are those who have developed and are implementing a supply chain philosophy. This will increasingly become a critical success factor as market demands of globalisation, customer expectations, customer satisfaction and technology drive the requirement to cooperate. 


\section{References}

Bowersox. D.J. and D.J. Closs 1996. Logistical Management: The Integrated Supply Chain Process McGraw-Hill International Editions

Chadwick, T.D., (1994) Partnerships and Preferred Supplier Arrangements: Do they just happen or are they created to order., 3rd International IPSERA Conference, 28-30 March, University of Glamorgan.

Chadwick, T.and Rajagopal, S. (1995) Strategic Supply Management:An Implementation Toolkit. Butterworth Heinmann. ISBN 0-7506-2253-9

Carlisle, J.A. and Parker, R.C. (1989) Beyond Negotiation: Redeeming Customer Supplier Relationships. John Wiley and sons Ltd.

Christopher, M. (1992) Logistics and Supply chain Management: Strategies for Reducing costs and Improving Services, Pitman Publishing

Cooper, J eds (1993) Strategy Planning in Logistics and Transportation, The Cranfield Management Research Series, Kogan Page

Dimancescu. D (1992) The Seamless Enterprise: Making Cross Functional Management Work Harper Business.

Ellram, L. M., and. Carr, A. (1994) Strategic Purchasing: A History and Review of the Literature. International Journal of Purchasing and Materials Management. Spring.:10-18.

Hastings, C. (1993) The New Organization: Growing the culture of Organizational Networking London: McGraw-Hill Book Company

Kanter, R.M. (1994). Collaborative Advantage. Harvard Business Review_(July, August): 96-108

Lamming, R. (1993) Beyond Partnerships: Strategies for Innovation and Lean Supply. 1st ed. Hemel Hempstead Prentice Hall

Macbeth. D.K and Ferguson, N (1994) Partnership Sourcing: An Integrated Supply Chain Approach London: Pitman Publishing

Macbeth, D.K., Murphy, M.D. Ferguson, N. and Neil G.C. (1993) Partnering Relationships: Barriers to Progress._PSERG 2nd International Conference Mohr, J., and Spekman. R.E. (1994) Characteristics of Partnership Success:

Partnership Attributes, Communication Behaviour and Conflict Resolution. Strategic Management Journal 15, 2, 135-52

Pfeffer, J., and Salancik, G.R. (1978) The External Control of Organizations: $A$ Resource Dependence Perspective New York: Harper and Row

Sako, M. (1992) Prices, Quality and Trust: Inter-Firm Relations in Britain and Japan. 1st ed. Cambridge: Cambridge University Press

Spekman. R.E., and Johnston, W.J. (1986) Relationship Management: Managing the Selling and Buying Interface. Journal of Business Research. 14, 519-31.

Porter, M.E. (1984) Strategic Interaction: Some Lessons from Industry Histories for Theory and Antitrust Policy. In Competitive Strategic Management, ed. P.B. Lamb,.B. 414-45. Englewood Cliffs, NJ: Prentice Hall 
Authors

Beverly Anne Wagner, MBA

Beverly is a research associate in the Centre for Supply Chain Management, since 1996. Currently completing a project titled "Implementing Partnering in the Supply Chain". She is also a 2nd year PhD student at the University of Glasgow. Research interests include, customer-supplier relationships, strategy, cross functional teams and the management of knowledge.

Tel: (44) 1419456461

Fax: (44) 1410427

Martin D. Murphy, BSc, MBA

Martin joined SCMG Ltd in 1992 as a senior consultant and has been MD since 1995. He has worked across a wide range of sectors and companies on an international basis helping them to develop and implement supply chain strategies with dramatic results. SCMG Ltd have been at the forefront of supply chain management and its development as a business philosophy. SCMG Ltd are cofounders of the Centre for Supply Chain Management and actively support and participate in new research in this area.

Tel: (44) 1416461

Fax: (44) 1410247

Esmond Haughey, Purchasing Director

Esmond's background is in Operations, Production, Manufacturing, Materials and Logistics and currently he is Procurement Director with IDV Operations Ireland. Esmond pioneered the partnering approach within IDV in Ireland and has used his experience of the IDV/Killeen partnership in other supplier organisations that include, SKW Biosystems and Jarvis Porter.

Tel: (353) 14051319

Fax: (353) 14051333 